\title{
The Role of Brain-Derived Neurotrophic Factor Receptors in the Mature Hippocampus: Modulation of Long-Term Potentiation through a Presynaptic Mechanism involving TrkB
}

\author{
Baoji Xu, ${ }^{1}$ Wolfram Gottschalk, ${ }^{3}$ Ana Chow, ${ }^{3}$ Rachel I. Wilson, ${ }^{2}$ Eric Schnell, ${ }^{2}$ Keling Zang, ${ }^{1}$ Denan Wang, ${ }^{1}$ \\ Roger A. Nicoll,, ${ }^{2}$ Bai Lu, ${ }^{3}$ and Louis F. Reichardt ${ }^{1}$ \\ ${ }^{1}$ Howard Hughes Medical Institute, Program in Neuroscience and Department of Physiology, and 2 Program in \\ Neuroscience and Department of Cellular and Molecular Pharmacology, University of California, San Francisco, California \\ 94143, and 3Unit on Synapse Development and Plasticity, National Institute of Child Health and Human Development, \\ National Institutes of Health, Bethesda, Maryland 20892
}

\begin{abstract}
The neurotrophin BDNF has been shown to modulate long-term potentiation (LTP) at Schaffer collateral-CA1 hippocampal synapses. Mutants in the BDNF receptor gene trkB and antibodies to its second receptor p75NTR have been used to determine the receptors and cells involved in this response. Inhibition of p75NTR does not detectably reduce LTP or affect presynaptic function, but analyses of newly generated trkB mutants implicate TrkB. One mutant has reduced expression in a normal pattern of TrkB throughout the brain. The second mutant was created by cre-loxP-mediated removal of TrkB in CA1 pyramidal neurons of this mouse. Neither mutant detectably impacts survival or morphology of hippocampal neurons. TrkB reduction, however, af-
\end{abstract}

fects presynaptic function and reduces the ability of tetanic stimulation to induce LTP. Postsynaptic glutamate receptors are not affected by TrkB reduction, indicating that BDNF does not modulate plasticity through postsynaptic TrkB. Consistent with this, elimination of TrkB in postsynaptic neurons does not affect LTP. Moreover, normal LTP is generated in the mutant with reduced TrkB by a depolarization-low-frequency stimulation pairing protocol that puts minimal demands on presynaptic terminal function. Thus, BDNF appears to act through TrkB presynaptically, but not postsynaptically, to modulate LTP.

Key words: TrkB; conditional mutant; CA1; long-term potentiation; presynaptic; neuronal survival
The neurotrophins promote survival of neurons from both the CNS and PNS in cell culture (for review, see Reichardt and Fariñas, 1997). These four closely related proteins (NGF, BDNF, NT-3, and NT-4) interact with Trk receptor tyrosine kinases. TrkA is activated by NGF; TrkB is activated by BDNF and NT-4; and TrkC is activated by NT-3. In some cells, NT-3 is able to activate all three Trk receptors (Huang et al., 1999). Engagement of the Trk receptors results in activation of several intracellular signaling pathways, including ras, phosphatidylinositol-3 kinase, and phospholipase $C \gamma 1$, which promote survival and differentiation. All four neurotrophins also bind to the unrelated receptor p75NTR, which activates ceramide turnover and the jun kinase cascade, promoting either cell motility or apoptosis, depending on cell type.

Both the neurotrophins and their receptors are expressed in the developing and adult CNS, and each of the neurotrophins has been shown to support survival and/or differentiation of CNS neurons in cell culture (for review, see Korsching, 1993). Despite this, comparatively few deficits have been seen in the brains of mice lacking individual neurotrophins or Trk receptors (for review, see Reichardt and Fariñas, 1997). In the hippocampus, the deficits observed include a small increase postnatally in granule cell apo-

\footnotetext{
Received Feb. 29, 2000; revised May 31, 2000; accepted June 28, 2000.
}

This work was supported by the Howard Hughes Medical Institute and National Institutes of Health (National Institute of Mental Health Grant 48200). L.F.R. is an investigator of the Howard Hughes Medical Institute. We thank Drs. Michael Stryker, Ardem Patapoutian, Eric Huang, and Song Hu for very helpful comments on this manuscript, and Drs. Liliana Minichiello and Rüdiger Klein for communication of results before publication. We also thank Regeneron Pharmaceuticals for providing TrkB-IgG, Drs. Mark Mayford and Eric Kandel for the promoter construct of $\alpha$ CaMKII, Juanito Meneses and Dr. Roger Pedersen (University of California San Francisco) for help with ES cell work, Judy Chang, Shan-Mei Xu, and Dr. Yuet Wai Kan for pronuclear injection of the CaMKcre construct, Drs. Klaus Rajewsky and Gail Martin for cre genes, Dr. Nigel Killeen for the pBS-lox-neo-tk-lox vector, and Dr. Chris Callahan for the tau-lacZ construct.

Correspondence should be addressed to Dr. Louis F. Reichardt, Department of Physiology and Howard Hughes Medical Institute, University of California, 533 Parnassus Avenue, San Francisco, CA 94143-0723. E-mail: lfr@cgl.ucsf.edu.

Copyright (C) 2000 Society for Neuroscience $0270-6474 / 00 / 186888-10 \$ 15.00 / 0$ ptosis and striking reductions in expression of calbindin, parvalbumin, and neuropeptide $\mathrm{Y}$ in GABAergic interneurons (Jones et al., 1994; Minichiello and Klein, 1996; Alcántara et al., 1997). Except for the NT-4 mutant, all of the neurotrophin- and Trk-deficient mice have quite limited postnatal life spans, seldom surviving beyond a couple of weeks. Consequently, it has been not possible to determine the requirements for these molecules during the entire span of CNS development or to use these animals to examine neurotrophin functions in adults.

The neurotrophins have been shown to modulate many aspects of synaptic transmission and neural plasticity (Lohof et al., 1993) (for review, see Thoenen, 1995; McAllister et al., 1999). Mechanisms underlying establishment of long-term potentiation (LTP) in the CA1 region of the hippocampus have been the subject of many studies (for review, see Malenka and Nicoll, 1999). LTP at these synapses is greatly reduced in BDNF homozygous and heterozygous mutant mice and can be rescued by exogenous BDNF (Korte et al., 1996; Patterson et al., 1996). Consistent with these results, LTP is also strongly inhibited in slices by application of the BDNF and NT-4 scavenger TrkB-IgG (Figurov et al., 1996; Kang et al., 1997).

Which cells and receptors are involved in the BDNF signaling circuit important for modulating LTP? Using cultured hippocampal neurons as a model system, BDNF has been shown to enhance transmitter release via a mechanism inhibitable by expression of a dominant negative variant of TrkB in presynaptic cells ( $\mathrm{Li}$ et al., 1998), suggesting a presynaptic locus via the receptor TrkB. In contrast, BDNF has been shown by different groups to enhance not only presynaptic transmitter release but also postsynaptic transmission through NMDA channels in cultured hippocampal neurons (Levine et al., 1995, 1998). Interneurons are also a potential locus for BDNF action, because BDNF deficiency clearly inhibits the differentiation of these neurons (Jones et al., 1994), and acute application of BDNF has been shown to decrease inhibition in slices from adult animals (Tanaka et al., 1997; Frerking et al., 1998). Thus, it is not certain whether the targets of BDNF relevant 
for LTP are presynaptic CA3 afferents, postsynaptic CA1 pyramidal cells, interneurons, or all three. It is similarly uncertain whether the relevant signaling important for modulating synaptic plasticity in vivo occurs through the endogenous TrkB receptor, the neurotrophin receptor $\mathrm{p} 75 \mathrm{NTR}$, or perhaps both. To analyze the cells and receptors important in modulating synaptic plasticity in the CA1 region of the hippocampus, we have used both antibody inhibition and genetic techniques to interfere with p75NTR and TrkB functions, respectively. Our results implicate TrkB but not p75NTR. Our data also indicate that the most important site of TrkB action is the presynaptic axons of the CA3 pyramidal neurons.

\section{MATERIALS AND METHODS}

Transgenic mouse production. The cre gene with a nuclear localization signal was removed from plasmid pML78 (kindly provided by Dr. Gail Martin, University of California, San Francisco, CA) and inserted into pNN265 (kindly provided by Drs. Mark Mayford and Eric Kandel, Columbia University, New York, NY) at its EcoRV site to generate pNN265cre. The $2.5 \mathrm{~kb}$ Not I fragment of pNN265-cre was composed of the cre transgene, an exon-intron splicing signal, and an SV40 polyadenylation signal and inserted into pN N279 (kindly provided by Drs. Mark Mayford and Eric Kandel) to construct a cre transgene expression vector. The $11 \mathrm{~kb}$ fragment containing the promoter for the $\alpha$ subunit of $\mathrm{Ca}^{2+} /$ calmodulindependent protein kinase II ( $\alpha \mathrm{CaMKII})$ and the cre transgene was released by SalI digestion and purified away from vector DNA. The cre founders were produced by pronuclear injection of the $11 \mathrm{~kb}$ SalI fragment into $\mathrm{C} 57 \mathrm{Bl} / 6$-DBA F1 hybrid zygotes. The cre founders were back-crossed into the $\mathrm{C} 57 \mathrm{Bl} / 6$ to produce transgenic offsprings. The genotypes of offspring mice were determined by PCR. The PCR primers for the cre transgene were 5'-GGATGAGGTTCGCAAGAACC-3' and 5'-CCATG AGTGAACGAACCTGG-3'. DNA samples $(\sim 0.5 \mu \mathrm{g})$ were amplified for 35 cycles $\left(1 \mathrm{~min}, 94^{\circ} \mathrm{C} ; 1.5 \mathrm{~min}, 65^{\circ} \mathrm{C}\right.$; and $\left.1.5 \mathrm{~min}, 72^{\circ} \mathrm{C}\right)$ on a Perkin-Elmer (Norwalk, CT) thermal cycler. These generated a product of $\sim 400 \mathrm{bp}$. The cre transgenic mice were back-crossed into the $\mathrm{C} 57 \mathrm{Bl} / 6$ background twice before they were bred with the floxed trkB mice.

Targeting construct and generation of a floxed trkB allele. A pair of PCR primers that surround the sequence encoding the signal peptide of TrkB were submitted to Genome Systems, Inc. (St. Louis, MO) to isolate P1 clones prepared from genomic DNA of the 129 strain of mice. The $10 \mathrm{~kb}$

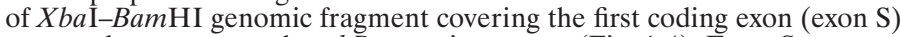
was used to construct the $\operatorname{trk} B$ targeting vector (Fig. $1 A$ ). Exon $\mathrm{S}$ covers a 346 bp $5^{\prime}$ untranslated region and a 211 bp coding region including 31 codons for the signal peptide. A ClaI site, which is located at the 19th bp of exon S, and a KpnI site, which is 112 bp downstream of exon S, were two critical restriction sites for construction of the targeting vector. The targeting vector was made by replacement of the ClaI-KpnI fragment that covers a majority of the exon S sequence and its downstream 112 bp intron sequence with an $\sim 14 \mathrm{~kb}$ of DNA fragment that includes a $4.4 \mathrm{~kb}$ trkB cDNA unit, a $4 \mathrm{~kb}$ PGKneo-tk selection cassette, and a $5 \mathrm{~kb}$ reporter gene, tau-lacZ, as well as three loxP sites (Fig. $1 A$ ). The trkB cDNA unit was generated by attachment of a $0.2 \mathrm{~kb}$ SV 40 polyadenylation signal sequence to the $3^{\prime}$ end of a $4.2 \mathrm{~kb} \mathrm{ClaI-EcoRI}$ trkB cDNA fragment that was isolated from pFRK44 (a gift from Dr. Rüdiger Klein, European Molecular Biology Laboratory, Heidelberg, Germany). The $4.2 \mathrm{~kb}$ trkB cDNA fragment covers the open reading frame for the full-length TrkB receptor tyrosine kinase and a $1.4 \mathrm{~kb} \mathrm{3}$ ' untranslated region. The trkB cDNA unit was fused into exon $\mathrm{S}$ at the ClaI site, where a sequence containing a loxP site and a BamHI site was inserted subsequently. The PGKneo-tk cassette flanked by two loxP sites is derived from plasmid pBS-lox-neo-tk-lox (kindly provided by Dr. Nigel Killeen, University of California, San Francisco, CA), where a $P G K-1$ promoter is followed by a neo gene, an internal ribosome entry sequence of encephalomyocarditis virus, a herpes simplex virus $t k$ gene, and a $P G K-1$ polyadenylation signal. The $5.5 \mathrm{~kb}$ reporter gene tau-lacZSV40 polyadenylation signal was derived from plasmid tau-lacZ (a gift from Dr. Chris Callahan, Salk Institute, San Diego, CA). The targeting vector contains $7 \mathrm{~kb}$ of homologous DNA (left arm) upstream of the first loxP site and $2.5 \mathrm{~kb}$ of homologous DNA (right arm) downstream of the tau-lac Z reporter gene.

The linearized targeting vector was electroporated into JM1 embryonic stem cells (Muller et al., 1997) grown on mitotically inactivated STO cells. After $8-10 \mathrm{~d}$ in selective medium $(300 \mu \mathrm{g} / \mathrm{ml} \mathrm{G} 418)$, colonies were picked, expanded, and screened for homologous recombination by Southern blotting using probes $\mathrm{A}$ and $\mathrm{B}$ as depicted in Figure $1 A$. The targeted embryonic stem (ES) cells were expanded and transfected with cre expressing plasmid pMC-cre (Gu et al., 1994; kindly provided by Dr. Klaus Rajewsky, University of Cologne, Cologne, Germany) by electroporation to transiently express Cre recombinase to remove the PGKneo-tk cassette. Colonies were picked, expanded, and screened for cre-mediated recombination by Southern blot analysis using probe C. Among more than 400 screened ES clones, 18 clones had both the trkB cDNA unit and the $P G K n e o-t k$ cassette removed, and one clone was identified to have Cremediated recombination between the second and the third loxP sites to generate a floxed trkB locus termed $f B Z$. The targeted ES cells with one $f B Z$ locus were injected into $\mathrm{C} 57 \mathrm{Bl} / 6$ blastocysts. Chimeric male mice were mated to $\mathrm{C} 57 \mathrm{Bl} / 6$ females to obtain germ line transmission (F1). The F1 heterozygous $f B Z$ mice were bred with CaMKcre transgenic mice. The F2 offsprings heterozygous for both the $f B Z$ allele and the CaMKcre transgene ( $f B Z /+$; CaMKcre/+) were mated with heterozygous $f B Z$ mice $(f B Z /+;+/+)$ to obtain trkB conditional knock-outs and their control animals. Animals heterozygous for both $f B Z$ and $C a M K c r e$ were also used to analyze the pattern of Cre-mediated trkB knock-out in the brain using 5-bromo-4-chloro-3indolyl- $\beta$-D-galactopyranoside (X-gal) staining and $\beta$-galactosidase immunocytochemistry.

Histological method. For X-gal staining, animals were anesthetized and transcardially perfused with $20 \mathrm{ml}$ of PBS, $40 \mathrm{ml}$ of $4 \%$ paraformaldehyde in PBS, and $20 \mathrm{ml}$ of PBS. The brains were cryoprotected in $30 \%$ sucrose, embedded in O.C.T. medium, and stored at $-80^{\circ} \mathrm{C}$. The frozen brains were sectioned at $20 \mu \mathrm{m}$ sagittally or coronally in a cryostat and processed for X-gal and immunofluorescence staining as described (Fariñas et al., 1996). For other histological staining, animals were anesthetized and transcardially perfused with $20 \mathrm{ml}$ of PBS and $40 \mathrm{ml}$ of $4 \%$ paraformaldehyde in PBS. The brains were post-fixed in $4 \%$ paraformaldehyde for $6-16 \mathrm{hr}$. Sagittal sections at $50 \mu \mathrm{m}$ were obtained with a Vibratome and collected in PBS. Nissl staining and immunocytochemistry were performed as described (Fariñas et al., 1996). Monoclonal antibodies against calbindin (1:1000), parvalbumin (1:1000), and MAP2 (1:1000) were from Sigma (St. Louis, MO). Antibodies against $\beta$-galactosidase were purchased from Promega (Madison, WI) (monoclonal, 1:250) and ICN Pharmaceuticals, Inc. (Costa Mesa, CA) (rabbit polyclonal, 1:3000). Monoclonal antibodies against the $\alpha$ subunit of CaMKII (1:100) were purchased from Affinity BioReagents, Inc (Golden, CO).

Northern blot, in situ hybridization, and Western blot. A trkB cDNA fragment from nucleotide 1386 to nucleotide 2054 was used as the probe for Northern hybridization and in situ hybridization. The antisense RNA probe for in situ hybridization of $\operatorname{trkB}$ mRNAs was labeled by using a Dig RNA labeling kit (Boehringer Mannheim, Indianapolis, IN) and hybridized with frozen sections according to protocols supplied by the manufacturer. The TrkB antibodies (RTB) for Western blot were raised against the TrkB extracellular domain (Huang et al., 1999). Northern and Western blots were quantified using a Fujifilm Multi-imager.

Electrophysiological recording. Transverse hippocampal slices $(400 \mu \mathrm{m})$ were prepared from $f B Z / f B Z$ mutants, trkB CA1-KO mutants, and their wild-type littermates (young adult, 2-3 months old). The slices were maintained in an interface chamber for both recovery $(2 \mathrm{hr})$ and recording and were exposed to an artificial atmosphere of $95 \% \mathrm{O}_{2}$ and $5 \% \mathrm{CO}_{2}$, as previously described (Pozzo-Miller et al., 1999). Perfusion medium [artificial CSF (ACSF), $34^{\circ} \mathrm{Cl}$ contained (in $\mathrm{mM}$ ): $\mathrm{NaCl}, 124 ; \mathrm{KCl}, 3.0 ; \mathrm{CaCl}_{2}$, 2.5; $\mathrm{MgCl}_{2}, 1.5 ; \mathrm{NaHCO}_{3}, 26 ; \mathrm{KH}_{2} \mathrm{PO}_{4}, 1.25 ;$ glucose, 10 ; and ascorbic acid, 2, pH 7.4. The perfusion rate was $15 \mathrm{ml} / \mathrm{hr}$. TrkB-IgG (kindly provided by Regeneron Pharmaceuticals, Inc., Tarrytown, NY) and the p75NTR antibody were added directly into the chamber and perfused for $60 \mathrm{~min}$ in a closed circle of $\sim 3 \mathrm{ml}$ at final concentrations of 1 and $50 \mu \mathrm{g} / \mathrm{ml}$, respectively. Field EPSPs were evoked in CA1 stratum radiatum by stimulation of Schaffer collaterals with twisted bipolar nichrome electrodes and recorded with ACSF-filled glass pipettes $(<5 \mathrm{M} \Omega)$ using Axoclamp-2B amplifiers (Axon Instruments, Foster City, CA). Test stimuli consisted of monophasic $200 \mu \mathrm{sec}$ pulses of constant current delivered by stimulus isolation units. Stimulus intensity was adjusted to evoke EPSPs of $\sim 1.3$ $\mathrm{mV}$. LTP was induced by two $1 \mathrm{sec}$ trains at $100 \mathrm{~Hz}$ separated by $20 \mathrm{sec}$ using the same test stimulus intensity. In each recording, synaptic efficacy (initial slope of EPSPs) was expressed as the percentage of baseline values recorded during the first $20 \mathrm{~min}$ before tetanus, and the magnitude of LTP was calculated at $45 \mathrm{~min}$ after tetanus. Synaptic responses to highfrequency stimulation (HFS) were calculated by taking the ratio of the last and first EPSP slopes during the $100 \mathrm{~Hz}$ train. EPSPs were digitized (3 $\mathrm{kHz}$ ), filtered at $10 \mathrm{kHz}$ (eight-pole Bessel filter), analyzed on-line, and stored on computers using P-clamp as well as custom developed software (provided by Dr. T. Inoue, The University of Tokyo, Tokyo, Japan).

For the input-output experiments, slices were bathed in ACSF containing $100 \mu \mathrm{M}$ DL-2-amino-5-phosphonovaleric acid (AP-5). Field recordings of the EPSPs and the presynaptic fiber volley were generated by a linear increase in the stimulation strength. Recordings that had a clear fiber volley (separated from the stimulation artifact) and an accompanying EPSP were used for analysis.

For whole-cell recording experiments, transverse hippocampal slices $(300 \mu \mathrm{m})$ were prepared from $f B Z / f B Z$ mutants and their wild-type littermates (17-25 d old). Slices were maintained in a submerged chamber for both recovery $(1 \mathrm{hr})$ and recording at room temperature $\left(24-28^{\circ} \mathrm{C}\right)$. Perfusion medium contained (in $\mathrm{mM}$ ): $\mathrm{NaCl}, 119 ; \mathrm{KCl}, 2.5 ; \mathrm{CaCl}_{2}, 2.5$; $\mathrm{MgSO}_{4}, 1.3 ; \mathrm{NaH}_{2} \mathrm{PO}_{4}, 1 ; \mathrm{NaHCO}_{3}, 26.2$; glucose, 11; and picrotoxin, 0.1, saturated with $95 \% \mathrm{O}_{2}$ and $5 \% \mathrm{CO}_{2}$. The perfusion rate was $1.5 \mathrm{ml} / \mathrm{min}$. A cut was made between CA1 and CA3 to prevent the propagation of epileptiform activity.

Somatic whole-cell voltage-clamp recordings were obtained from visually identified CA1 pyramidal cells using 3-5 M $\Omega$ glass electrodes filled with (in $\mathrm{mm}$ ): Cs-gluconate, 117.5 ; $\mathrm{CsCl}, 2.5$; tetraethylammonium- $\mathrm{Cl}, 10$; QX-314, 5 (chloride salt; Precision Biochemicals, Vancouver, British Columbia, Canada); NaCl, 8; HEPES, 10; EGTA, 0.2; Mg-ATP, 4; and $\mathrm{Na}_{3}$-GTP, 0.3, pH 7.2, 280 mOsm. Monosynaptic EPSCs were evoked in stratum radiatum at $0.1 \mathrm{~Hz}$, filtered at $2 \mathrm{kHz}$, and digitized at $5 \mathrm{kHz}$. Cells 
A
wild-type
trkB locus
trkB targetin
vector

Figure 1. Targeting disruption of the trkB gene. $A$, Schematic diagrams of the trkB gene, the targeting construct, and the targeted trkB locus. The probes used for screening and the expected Southern blot fragments are indicated. The homology arms are represented in thick lines. $B$, BamHI; Bs, multiple BamHI sites; C, ClaI; $H$, HindIII; K, KpnI; X, XbaI. B, Southern blot analyses of representative tail DNA sample. DNA was digested with BamHI and blotted with probe A or probe C. Using probe A, 10.5 and $7.5 \mathrm{~kb}$ bands are generated by digestion of the wild-type trkB and the targeted trkB alleles, respectively. Probe $C$ does not detect any band from the wild-type allele but detects a 1.3 $\mathrm{kb}$ band from the floxed trkB allele. $C$, Northern blot analysis of trkB mRNAs. Fifteen micrograms of total brain RNA were loaded onto each lane. $+/+$, Wildtype; $f B Z / f B Z$, homozygous for the $f B Z$ allele. Note the presence of a single RNA from the floxed trk $B$ allele. $D$, Western blot analysis of TrkB protein. Protein extracts were prepared from the brains of wild-type and $f B Z / f B Z$ homozygous mice. Forty micrograms of protein were loaded onto each lane.

in which the series or input resistances changed by $>25 \%$ during the duration of the experiment were discarded.

\section{RESULTS}

\section{Generation of mice expressing reduced levels of TrkB kinase}

To reveal the roles of TrkB signaling on hippocampal structure and function in adult animals, we have used the bacteriophage cre/loxP recombination system to generate viable, cell type-specific trkB mutant mice that can grow into the adulthood (Gu et al., 1994; Tsien et al., 1996). These mice can be used to examine the consequences of deletion of $\operatorname{trk} B$ in defined subpopulations of adult hippocampal cells. As the first step in this procedure, we designed a mutant $t r k B$ allele in which the first coding exon of the $t r k B$ gene (exon $\mathrm{S}$ ) is replaced with a $\operatorname{trkB}$ cDNA unit followed by an SV40 polyadenylation signal. This unit was flanked by two loxP sites probe A

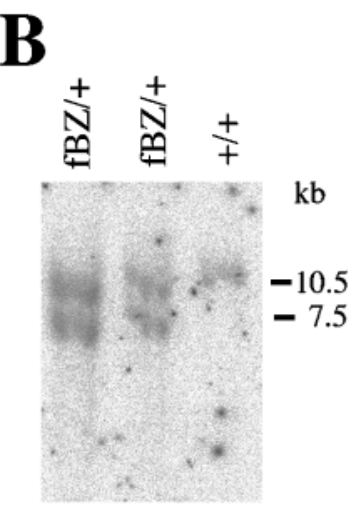

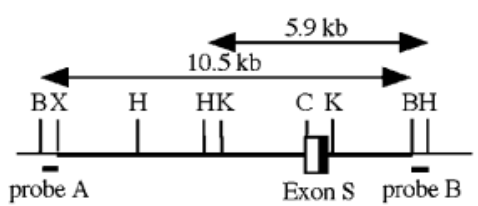
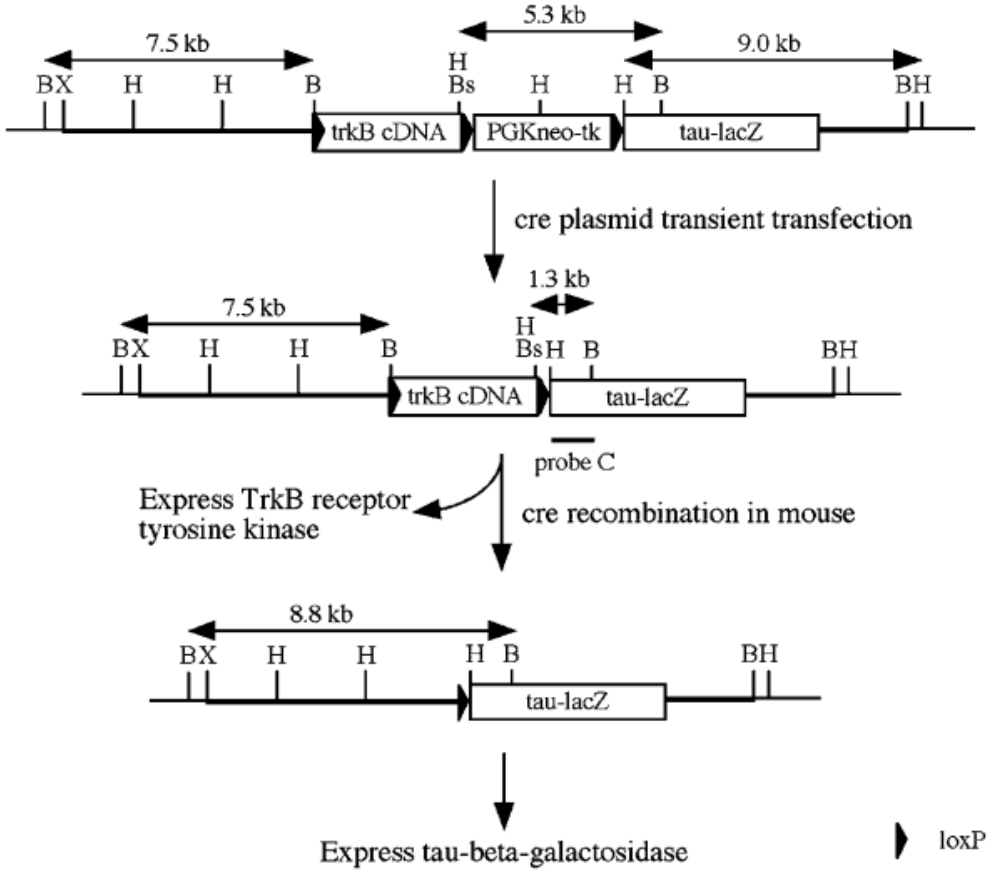

Express tau-beta-galactosidase

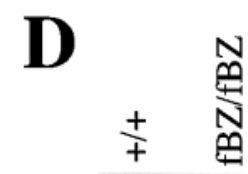

$\mathrm{kb}$

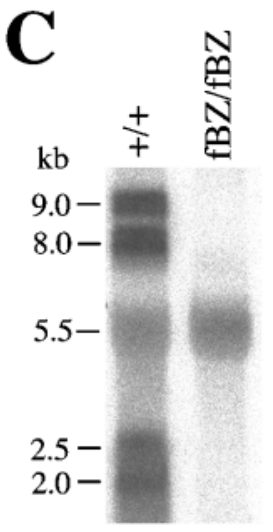

TrkB $100 \% \quad 24.1 \pm 4.4 \%$ probe $\mathrm{C}$

(floxed), followed in turn by a tau-lac $Z$ reporter gene (Fig. 1A). This allele, named $f B Z$, was designed so that the $\operatorname{trk} B$ cDNA unit would be transcribed under normal control of the $\operatorname{trk} B$ promoterenhancer complex. Transcription starts at least one exon upstream of exon $\mathrm{S}$, because exon $\mathrm{S}$ does not cover all 5' untranslated sequences of $t r k B$ mRNAs. Except for a 112 bp sequence immediately downstream of exon $\mathrm{S}$, no sequence in the $\operatorname{trk} B$ gene was deleted in the $f B Z$ allele (Fig. $1 A$, middle). The SV40 poly(A) signal at the $3^{\prime}$ end of the $\operatorname{trk} B$ cDNA unit was included to terminate transcription before the tau-lac $Z$ sequence. In the rare event that messages escape termination, translation will be stopped by the multiple stop codons in the $1.4 \mathrm{~kb} \mathrm{3}$ trkB untranslated sequence. Thus, the tau-lac $Z$ sequence will not be expressed before the floxed $t r k B$ cDNA unit is deleted by Cre-mediated recombination. In contrast, after the floxed trkB cDNA unit is deleted, the 
tau-lac $Z$ will be fused into the $5^{\prime}$ end of exon $\mathrm{S}$ and will be expressed under the control of the trkB promoter (Fig. $1 A$, bottom). Therefore, the expression of the tau-lac $Z$ product tau- $\beta$ galactosidase makes it possible to identify cells that in control animals would express TrkB but in an $f B Z$ homozygote lose TrkB expression after Cre-mediated recombination. The tau sequence was fused to $l a c Z$ in an effort to target $\beta$-galactosidase to the axons and apical dendrites in addition to the cell soma (Callahan et al., 1994), facilitating comparisons of the morphologies of neurons in the presence and absence of TrkB.

Using ES cell technology, the $f B Z$ allele was introduced into mice where it can be identified by Southern blot analyses with probe A, which detects a $10.5 \mathrm{~kb} B a m \mathrm{HI}$ fragment from the wild-type $t r k B$ allele and a $7.5 \mathrm{~kb} B a m \mathrm{HI}$ fragment from the $f B Z$ allele, as well as with probe $C$, which only detected the $1.3 \mathrm{~kb}$ $B a m$ HI fragment of the $f B Z$ allele (Fig. $1 B$ ). As expected, only a single trkB mRNA $(5.5 \mathrm{~kb})$ was detected in homozygous $f B Z$ mice ( $f B Z / f B Z$ ) instead of the multiple mRNAs encoded by the wildtype trkB locus (Fig. $1 C$ ). Surprisingly, the amount of trkB mRNA in the $f B Z / f B Z$ brain was only $33 \%$ of the sum of the two mRNAs $(5.5$ and $9.0 \mathrm{~kb})$ encoded by the wild-type allele, which has been shown to encode the kinase-containing isoform of TrkB (Klein et al., 1990). Similarly, the level of full-length TrkB protein in $f B Z /$ $f B Z$ mice is only $24.1 \pm 4.4 \%(n=3)$ of the kinase-containing isoform in wild-type mice (Fig. $1 D$ ). Immunocytochemical analyses using anti-TrkB antibodies indicate that TrkB is expressed at reduced levels but in a normal pattern of expression throughout the brain (data not shown). As predicted, no expression of truncated isoforms of TrkB was observed in $f B Z / f B Z$ mutants. Mice homozygous for the $f B Z$ allele are viable and can live $>3$ months.

\section{Generation of mice lacking TrkB in hippocampal CA1 pyramidal neurons}

To create a cell- and region-specific mutation of the $\operatorname{trk} B$ gene, we used the promoter for $\alpha \mathrm{CaMKII}$ to generate a transgenic mouse line in which the promoter drives expression of the cre transgene (termed CaMKcre) in the forebrain (Burgin et al., 1990; Mayford et al., 1995). Crossing of $f B Z /+$ and CaMKcre mice led to deletion of the floxed trkB cDNA in cre-expressing cells. The deletion of the trkB cDNA in TrkB-expressing cells results in the expression of tau- $\beta$-galactosidase, which can be easily identified by the X-gal staining or anti- $\beta$-galactosidase antibodies. To determine which cells were affected, mice heterozygous for both CaMKcre and $f B Z$ $(\mathrm{fBZ} /+; \mathrm{CaMKcre} /+)$ were used to examine in detail the specific regions and cell types in which cre recombination has occurred. The CaMKcre transgenic line used in this study mediates deletion of the $f B Z$ allele in many cells of the neocortex, the hippocampus, the striatum (caudate and putamen), the amygdala, and the substantia nigra (Fig. 2; data not shown).

In the hippocampus, tau- $\beta$-galactosidase expression is almost exclusively limited to the CA1 region (Fig. $2 C$ ). Very few cells in the $\mathrm{CA} 3$ region and dentate gyrus are positive for $\mathrm{X}$-gal staining (Fig. $2 C$ ), although the trkB gene is expressed in all regions of the hippocampus (Altar et al., 1994; Yan et al., 1997). In previous work, different $\alpha \mathrm{CaMKII}$-cre transgenes have been shown to differ significantly in their expression patterns (Tsien et al., 1996), so it is not surprising that expression of this transgene does not match perfectly the endogenous expression pattern of $\alpha$ CaMKII. As assessed using tau- $\beta$-galactosidase expression, significant recombination does not begin before postnatal day 14 (P14), because at that age no tau- $\beta$-galactosidase is seen in the hippocampus (Fig. $2 A$ ). At P29 (Fig. $2 B$ ), the pattern of tau- $\beta$-galactosidase expression is very similar to the pattern observed at P68 (Fig. 2C).

To determine which neurons in the CA1 region lose TrkB as a result of CaMKcre-mediated recombination, antibodies to various cell-specific markers were used together with antibodies to $\beta$-galactosidase. In recent work, CaMKII has been shown to be expressed exclusively in excitatory pyramidal neurons within the CA1 region (Sík et al., 1998; Z hang et al., 1999). Co-staining with anti- $\alpha \mathrm{CaMKII}$ and anti- $\beta$-galactosidase demonstrates that $\operatorname{trk} B$ has

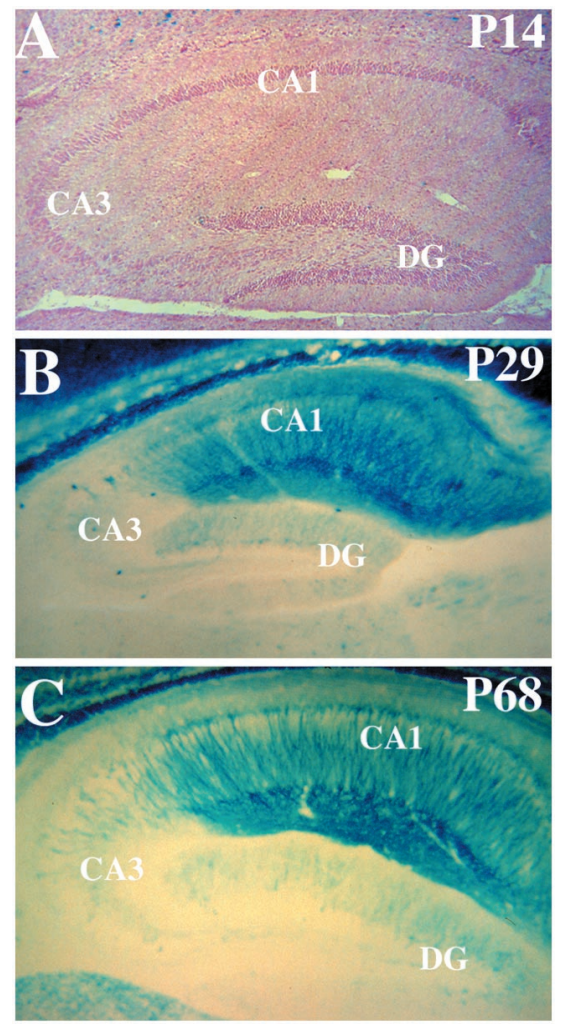

Figure 2. Pattern of $\operatorname{trkB}$ recombination in the brain. X-gal staining of representative hippocampi from $\mathrm{fBZ} /+; \mathrm{CaMKcre} /+$ mice is shown. The ages of the mice are indicated. The section shown in $A$ was counterstained with nuclear fast red. Note that the X-gal staining in the hippocampus is essentially limited to the CA1 region in both $\mathrm{P} 29$ and P68 animals. $c c$, Corpus callosum; $D G$, dentate gyrus; $N t x$, neocortex; $S N$, substantia nigra; $T h$, thalamus.

been deleted in these neurons with high efficiency (Fig. $3 A-C$ ). In sections from $f B Z /+; C a M K c r e /+$ mice, which contain only one copy of $f B Z, 91$ of $95 \alpha$ CaMKII-positive CA1 pyramidal neurons also expressed tau- $\beta$-galactosidase $(96 \%)$. In similar sections from mice containing two copies of $f B Z$ ( $f B Z / f B Z ; C a M K c r e /+)$, at least one allele of $f B Z$ was deleted in all neurons expressing $\alpha \mathrm{CaMKII}$ (76 of $76 \alpha$ CaMKII-positive neurons expressed tau- $\beta$ galactosidase). Assuming that different alleles are targeted independently within these neurons, both copies of the $f B Z$ allele must be deleted in $92 \%(0.96 \times 96 \%)$ of these neurons. If targeting of different alleles within the same cell is linked, the efficiency of $f B Z$ deletion would be even higher. These results indicate that the $f B Z$ allele is deleted in essentially all CA1 pyramidal neurons of the $f B Z / f B Z ; C a M K c r e /+$ mutant (trkB CA1-KO). Importantly, no examples of cells expressing $\beta$-galactosidase in the absence of $\alpha \mathrm{CaMKII}$ were seen, so action of this CaMKcre transgene appears to be restricted to pyramidal neurons in the CA1 region. Consistent with results from X-gal staining (Fig. 2), only 7\% (6 of 83) of $\alpha \mathrm{CaMKII}$-positive CA3 pyramidal neurons also expressed tau- $\beta$ galactosidase, indicating that the majority of CA3 pyramidal neurons continue to express TrkB.

To confirm that these CA1 neurons no longer expressed trkB mRNA, the patterns of expression of $\operatorname{trk} B$ mRNA were analyzed by in situ hybridization of sections of control $(f B Z / f B Z)$ and CA1-KO ( $f B Z / f B Z ; C a M K c r e /+)$ hippocampi. Results, presented in Figure 3, $D$ and $E$, demonstrate that there is strong expression of $\operatorname{trk} B$ mRNA in the CA3 and CA1 regions of the control. In CA1-KO, however, expression of $\operatorname{trk} B$ mRNA is almost entirely eliminated in the CA1 region, although it continues to be expressed normally in the CA3 region. These data provide independent evidence that cre derived from this CaMKcre transgene is active in CA1 but not in CA3. The results are also consistent with evidence described above, indicat- 

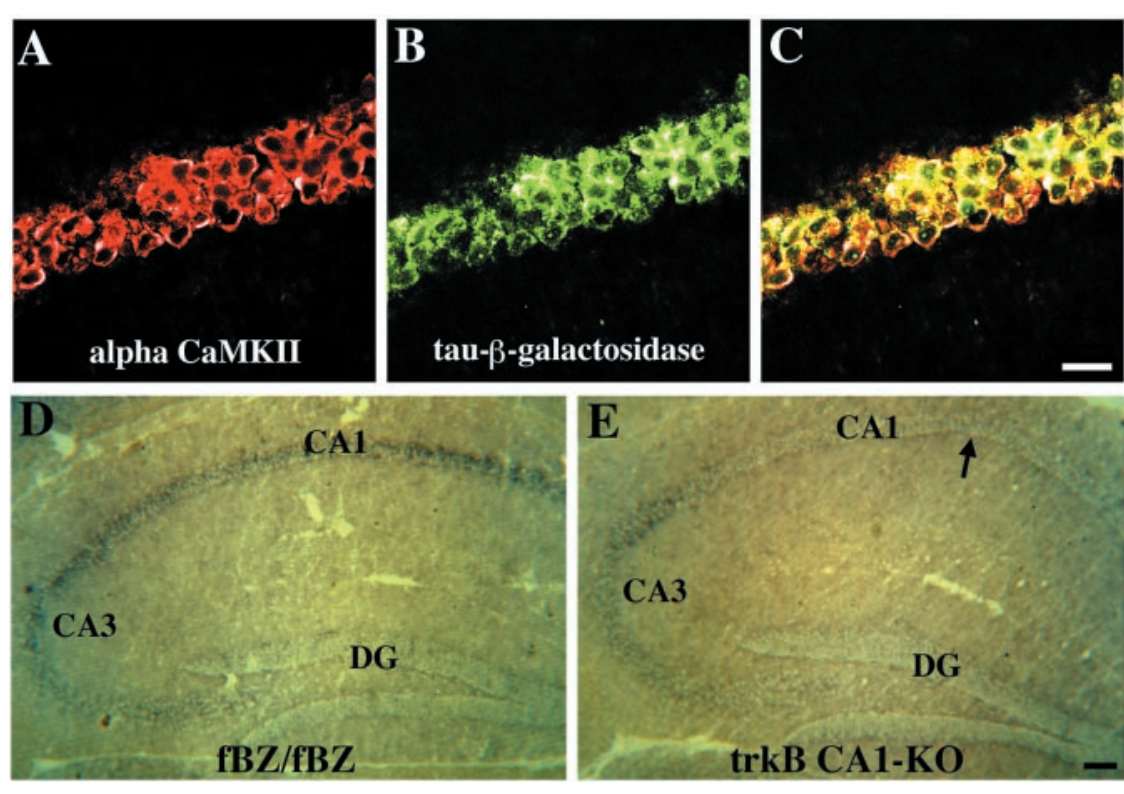

Figure 3. Lack of trkB expression in CA1 pyramidal neurons. $A-C$, Immunofluorescent staining for $\alpha \mathrm{CaMKII}$ and $\beta$-galactosidase in the CA1 region of a P55 trkB CA1-KO ( $\mathrm{BBZ} / \mathrm{fBZ}$;CaMKcre/+) mouse. Note that all neurons positive for $\alpha \mathrm{CaMKII}$ are also positive for $\beta$-galactosidase immunoreactivity. $D, E$, In situ hybridization of trkB mRNAs from 3-month-old $f B Z / f B Z$ $(D)$ and $\operatorname{trkB}$ CA1-KO $(E)$ mice. The arrow in $E$ indicates some positive cells in the CA1 ventral side. Scale bar: $A-C, 20 \mu \mathrm{m} ; D, E, 100 \mu \mathrm{m}$. ing that $\operatorname{trk} B$ expression is very efficiently eliminated from CA1 pyramidal neurons.

Pyramidal neurons are not the only neurons in the hippocampus that express TrkB. In addition to pyramidal neurons, the CA1 region also contains scattered GABAergic interneurons, a majority of which express calbindin (Shetty and Turner, 1998). GABAergic interneurons have been shown to express TrkB and to be responsive to BDNF (Ip et al., 1993; Tanaka et al., 1997; Vicario-Abejón et al., 1998). Because these neurons do not express $\alpha$ CaMKII (Sík et al., 1998; Zhang et al., 1999), they are unlikely to be affected by expression of the CaMKcre transgene. Indeed, examination of trkB mRNA expression in CA1-KO reveals that in the ventral portion of CA1 there are a few TrkB-expressing cells, which are most likely interneurons (Fig. 3E, arrow). To determine the identity of the tau- $\beta$-galactosidase negative neurons in the ventral CA1, brain sections were stained with calbindin antibodies. Immunohistochemistry on sections from wild-type and trk $B$ mutant mice shows that some neurons in the CA1 ventral layer express calbindin (Fig. $4 G-I)$. In the $\mathrm{fBZ} /+$;CaMKcre/+ mouse, double immunofluorescence staining for calbindin and $\beta$-galactosidase indicates that all calbindin-positive interneurons in the CA1 region are negative for $\beta$-galactosidase (data not shown). Because hippocampal interneurons express the TrkB receptor (Altar et al., 1994), these neurons would have expressed the tau- $\beta$-galactosidase reporter after cremediated recombination. Consequently, these results indicate that the $\operatorname{trkB}$ cDNA is not deleted in interneurons in CA1. Taken together, our studies using cell-specific markers argue that, in this transgenic line, the $\operatorname{trk} B \mathrm{cDNA}$ is only deleted in pyramidal neurons and not in other cells within the CA1 region.

\section{Effects of reduced expression of TrkB on hippocampal anatomy}

In studies reported elsewhere (Xu et al., 2000), deletion of the $f B Z$ allele in neocortical pyramidal neurons has been shown to have dramatic effects on cortical anatomy, including alterations in dendritic arbors, loss of pyramidal neurons, and reductions in thickness of cortical layers II/III and V. In contrast, results presented in Figures 4 and 5 indicate that reducing expression of TrkB within the entire hippocampus or deletion of $\operatorname{trk} B$ within CA1 pyramidal neurons does not affect the gross morphology of the hippocampus or the morphologies of CA1 pyramidal cells and interneurons. As revealed by Nissl staining (Fig. $4 A-C$ ), the overall structures of the hippocampi of adult mice were not altered in the $f B Z / f B Z$ hypomorphic mutant or the $\operatorname{trkB} \mathrm{CA} 1-\mathrm{KO}$. When the hippocampi of adult mice were examined using antibodies to the interneuron markers parvalbumin and calbindin (Shetty and Turner, 1998), interneurons appeared to be present in normal numbers and to have normal morphologies in each of these mutant strains (Fig. 4, compare $D$ with $E, F$; $G$ with $H, I)$. Dendritic morphologies were examined in the CA1 regions of wild-type, $f B Z / f B Z$ hypomorphic mutant, and trkB CA1-KO mice at P75, using antibodies to the dendritic marker MAP2. Again, no obvious morphological differences were seen in either mutant mouse strain (Fig. 5, compare $A$ with $B, C)$. Tau was intentionally fused to the $\beta$-galactosidase reporter with the expectation that it would facilitate detection of differences in axonal or dendritic morphology in mutant animals (Callahan and Thomas, 1994). In studies on the neocortex, trkB deletion has been shown to alter pyramidal cell morphology, as assayed with this reporter or with biocytin injections (Xu et al., 2000). In the CA1 region of the hippocampus, though, deletion of $\operatorname{trk} B$ has no effect on the dendritic morphologies of targeted pyramidal neurons, as assessed using this reporter (Fig. 5, compare $D$ with $E$ ). Thus, the morphology of the hippocampus is not obviously affected by a reduction in TrkB or by specific elimination of TrkB within CA1 pyramidal neurons. Consequently, these two lines of animals with perturbed TrkB expression provided valuable reagents for studying mechanisms of BDNF modulation of synaptic transmission and plasticity.

\section{Effects of TrkB reduction on CA1 long-term potentiation}

Recent studies have demonstrated that BDNF can modulate hippocampal LTP (Korte et al., 1995; Figurov et al., 1996; Patterson et al., 1996; Kang et al., 1997). It is not clear whether the effects of BDNF on LTP depend on activation of the TrkB receptor tyrosine kinase or instead requires activation of p75NTR. Compared with wild-type littermates, the level of the TrkB receptor tyrosine kinase is only $24 \%$ in $f B Z / f B Z$ mice (Fig. $1 D$ ). Thus, this line of mice can be used to determine whether the level of TrkB can limit either the magnitude or efficiency of generation of hippocampal CA1 LTP. To examine these possibilities, we used standard extracellular field recording techniques to monitor field EPSPs and applied tetanic stimulation (two $1 \mathrm{sec}$ trains at $100 \mathrm{~Hz}, 20 \mathrm{sec}$ apart) to Schaffer collaterals to induce LTP in the CA1 region. In the first series of experiments, we examined whether the magnitude of LTP was reduced in $f B Z / f B Z$ mice. Hippocampal slices from wild-type mice exhibited a robust potentiation of synaptic efficacy, lasting to the end of the recordings $(n=5$ mice; Fig. $6 A)$. The same tetanic stimulation was able to induce LTP in $f B Z / f B Z$ mice, but the magnitude of LTP was reduced significantly $(n=4$ mice; Fig. $6 A)$. Next we performed recordings on a larger number of slices and animals to determine whether the percentage of slices exhibiting LTP in the $f B Z / f B Z$ mice was also reduced when compared with the 


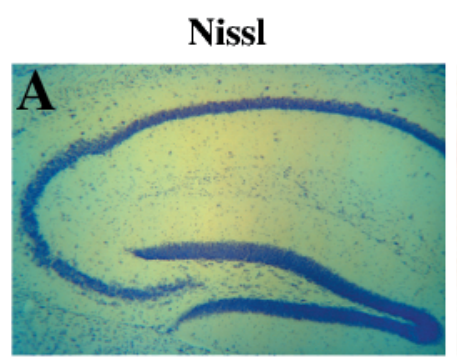

\section{Parvalbumin}
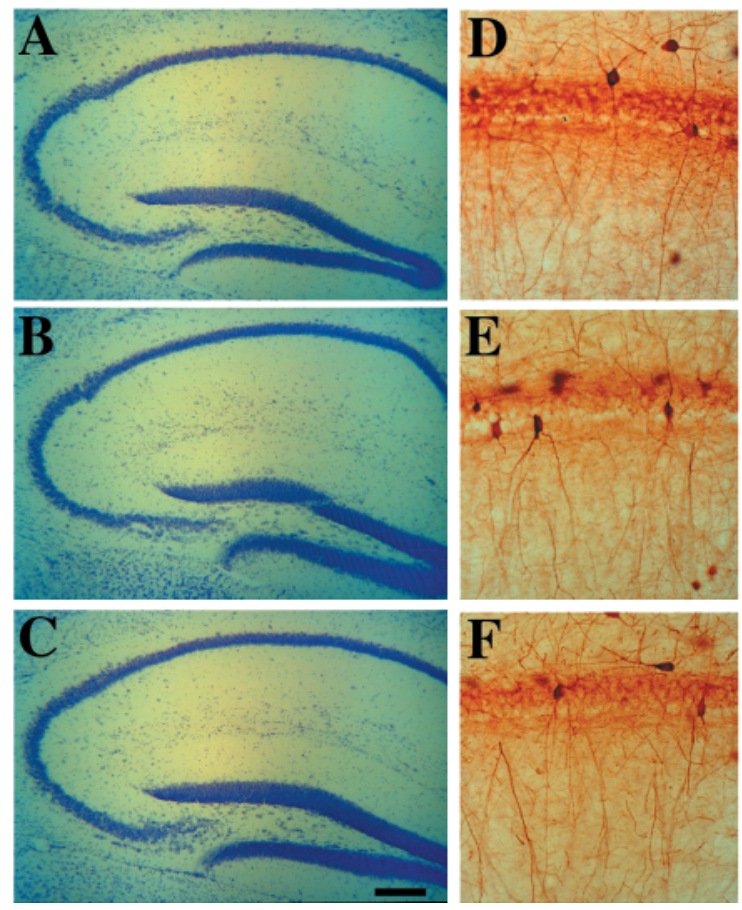

\section{Calbindin}
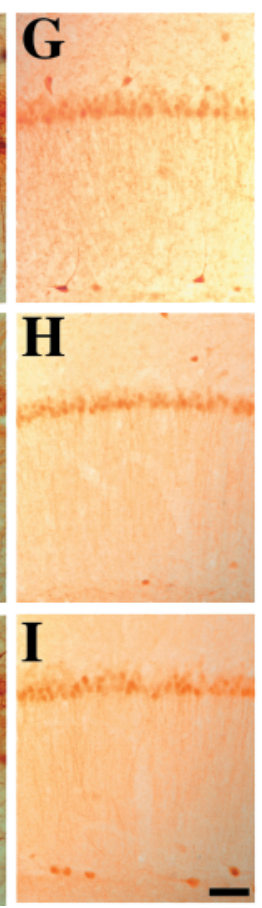

$+/+$

\section{$\mathbf{f B Z} / \mathbf{f B Z}$}

Figure 4. Normal hippocampal structure in trkB mutants. Histological stainings were performed on sagittal sections of mouse brains with genotypes as indicated on right. $A-C$, Nissl-stained hippocampi of adult mice. $D-I$, The hippocampal CA1 regions of adult mice were stained immunohistochemically for parvalbumin $(D-F)$ and calbindin $(G-I)$. Note that there are no significant differences among three genotypes of animals in the gross anatomical structure of the hippocampus and the number and morphology of interneurons positive for calbindin or parvalbumin. Scale bar: $A-C, 200 \mu \mathrm{m} ; D-I, 50 \mu \mathrm{m}$. wild-type animals (Fig. 6B). Among all the recordings we obtained, $78.8 \%$ of slices from $+/+$ mice exhibited LTP $(n=33$ slices, eight mice), whereas $50 \%$ of slices derived from $f B Z / f B Z$ mice showed LTP ( $n=34$ slices, six mice). Moreover, the mean slope of the EPSPs at 45 min after tetanus was $149 \pm 2.9 \%$ of baseline in wild
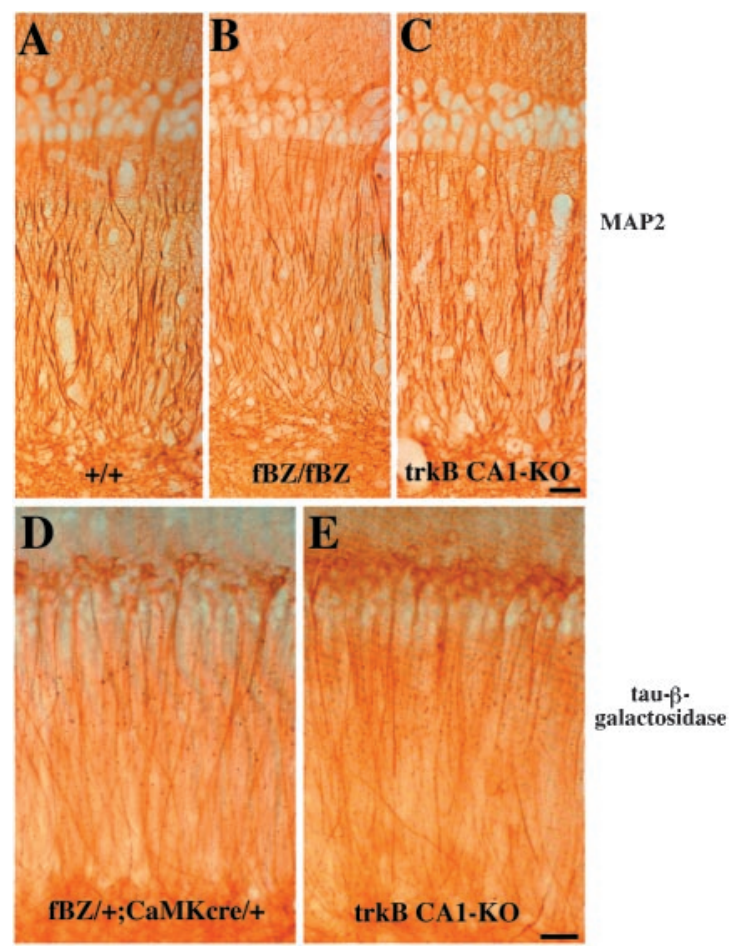

Figure 5. Normal dendritic morphologies of CA1 pyramidal neurons in the trkB CA1-KO. Histological stainings were performed on sagittal sections of mouse brains with genotypes as indicated. The hippocampal CA1 regions of adult mice were stained immunocytochemically for MAP2 $(A-C)$ and $\beta$-galactosidase $(D, E)$. Note that there are no significant differences in the dendritic structure of CA1 pyramidal neurons revealed by MAP2 and $\beta$-galactosidase immunohistochemistry among control mice and trkB mutants. Scale bar: $A-C, 20 \mu \mathrm{m} ; D, E, 50 \mu \mathrm{m}$. type but only $131 \pm 7.1 \%$ in $f B Z / f B Z$ mice (Fig. $6 D ; p<0.05$, two-tailed $t$-test). Consistent with previous reports demonstrating that reductions in the ligand BDNF impair LTP (Korte et al., 1995; Patterson et al., 1996; Pozzo-Miller et al., 1999), these results indicate that tetanus-induced hippocampal LTP is significantly impaired by reducing the level of TrkB protein.

\section{Effects of p75NTR inhibition on CA1 long-term potentiation}

Besides the TrkB receptor, BDNF can also interact with p75NTR. p75NTR immunoreactivity has not been detected in CA3 and CA1 neurons (Pioro and Cuello, 1990), but low levels of p75NTR may have escaped detection. To examine whether p75NTR signaling contributes to CA1 LTP, we incubated hippocampal slices from wild-type animals with anti- p75NTR IgG (REX IgG). In previous work, REX IgG has been used by several groups to inhibit p75NTR-mediated responses, such as apoptosis, in vivo (LucidiPhillipi et al., 1996). Treatment of hippocampal slices with this antibody does not significantly impair LTP (Fig. $6 C ; n=4$ for control and 5 for REX IgG-treated slices). Therefore, BDNF effects on LTP do not appear to be mediated through p75NTR.

\section{Site of TrkB signaling important for modulating CA1 long-term potentiation}

Results presented above have demonstrated that BDNF modulation of LTP at CA1 synapses is dependent on TrkB, not p75NTR, but have not identified the cells in which TrkB signaling is required. Considerable debate exists regarding the site at which BDNF acts to modulate synaptic efficacy in the hippocampus. BDNF has been reported to potentiate basal excitatory synaptic transmission via a presynaptic mechanism in cultured hippocampal neurons (Lessmann et al., 1994; Li et al., 1998) and in hippocampal slices (Kang and Schuman, 1995) (but see Figurov et al., 1996; Patterson et al., 1996; Tanaka et al., 1997; Frerking et al., 1998; Gottschalk et al., 1998). Additionally, BDNF increases the ability of the presynaptic terminal to release transmitter repetitively at high frequency (Figurov et al., 1996; Gottschalk et al., 1998). In contrast, a number of studies have also demonstrated that BDNF can act postsynaptically by enhancing NMDA receptor-mediated currents in mixed hippocampal neurons in culture (Levine et al., 1995, 1998; Jarvis et al., 1997). To test the role of postsynaptic TrkB in modulating LTP at 
Figure 6. Impairment of LTP in hippocampal CA1 synapses of $f B Z / f B Z$ and trkB CA1-KO mice. All data in this figure and Figure 7 are expressed as mean \pm SEM. $A$, Time courses of synaptic potentiation induced by tetanic stimulation in CA1 synapses of hippocampal slices from different genotypes. Field EPSPs were recorded in the CA1 area, and tetanus $(2 \times 1 \mathrm{sec}, 100 \mathrm{~Hz}, 20 \mathrm{sec}$ apart $)$ was applied to Schaffer collaterals at time 0. Synaptic efficacy (initial slope of EPSPs) is expressed as the percentage of baseline values recorded during the first 20 min before tetanus. Each data point represents the averaged values of recordings at that particular time point. Wild-type, $n=5$ mice; $f B Z / f B Z, n=$ 4 mice; trkB CA1-KO, $n=7$ mice. $B$, Percentage of successful LTP recordings for wild-type, $f B Z / f B Z$, and trkB CA1-KO mice. LTP was judged successful if, at $45 \mathrm{~min}$ after the tetanus, the slope of the EPSP was $>125 \%$ of the baseline. Wild-type, $n=35$ slices from eight mice; $f B Z / f B Z$, $n=34$ slices from six mice; $\operatorname{trkB}$ CA1-KO, $n=50$ slices from seven mice. $C$, Effect of p75NTR antibodies on LTP Slices from wild-type animals were treated with or without p75NTR antibodies $(50 \mu \mathrm{g} / \mathrm{ml}$ in ACSF). The magnitude of LTP was expressed as a percentage of the EPSP slopes before and $60 \mathrm{~min}$ after tetanus. The control and antip75NTR antibody-treated groups $(n=4$ and 5 slices, respectively) are not statistically different (two-tailed $t$ test, $p=0.6)$. $D$, Magnitude of LTP in slices from wild-type, $f B Z / f B Z$, and trkB CA1-KO mice and trkB CA1-KO slices treated with TrkB-IgG. Synaptic efficacies $45 \mathrm{~min}$ after the

$\mathbf{A}$

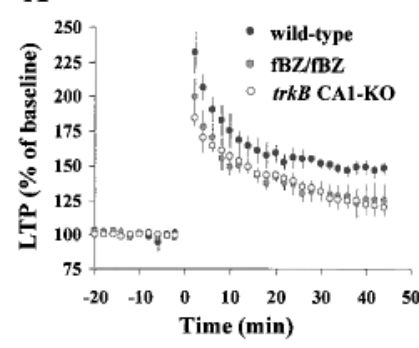

D

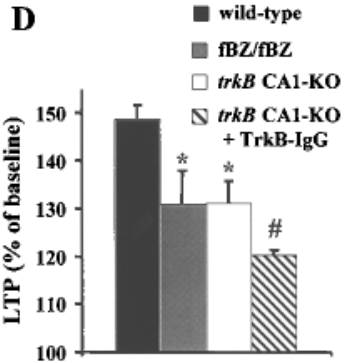

B

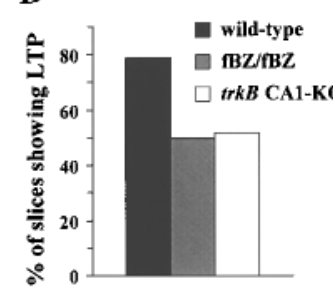

$\mathbf{E}$

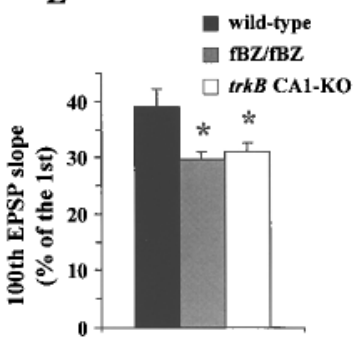

C

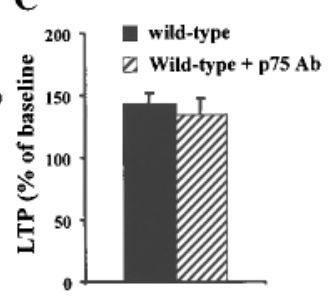

$\mathbf{F}$

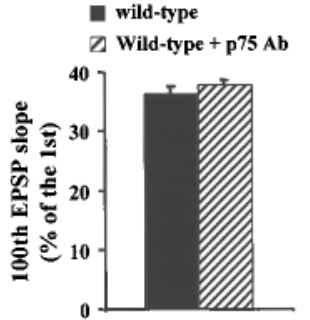

tetanus from each animal are averaged and expressed as the percentage of baseline values. Wild-type, $n=8$ mice; $f B Z / f B Z, n=6$ mice; trkB CA1-KO,

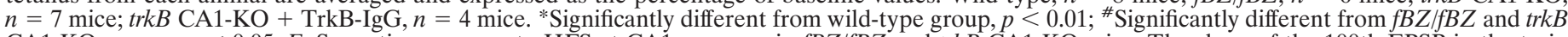
CA1-KO groups, $p<0.05$. E, Synaptic responses to HFS at CA1 synapses in $f B Z / f B Z$ and trkB CA1-KO mice. The slope of the 100 th EPSP in the train is presented as the percentage of the first EPSP slope. *Significantly different from wild-type, Student's $t$ test, $p<0.001$. $F$, Synaptic responses to HFS at CA1 synapses of wild-type hippocampal slices treated with or without anti-p75NTR IgG. The slope of the 100th EPSP in the train is presented as the percentage of the first EPSP slope. There is no difference between the two groups $[n=4$ for wild-type and $n=5$ for p 75 antibody $(A b)$-treated groups, two-tailed $t$ test, $p=0.33$.

the Schaffer collateral $\rightarrow$ CA1 synapses, we used hippocampal slices from the trkB CA1-KO mice, in which the TrkB receptor has been deleted only in the postsynaptic CA1 pyramidal neurons and not in the CA3 pyramidal neurons, which are the source of the presynaptic Schaffer collaterals (Figs. 2, 3). As documented in Figure 6, $A$ and $D$, the average magnitude of LTP recorded from CA1 synapses of CA1-KO mice was markedly reduced compared with that from wild-type mice. However, the CA1 synapses from CA1-KO mice exhibited essentially the same LTP magnitude as those from $f B Z$ / $f B Z$ mice (Fig. $6 D ; n=8$ mice). Moreover, $52 \%$ of the slices from the trkB CA1-KO mice showed LTP (defined as EPSP slope $>$ $125 \%$ of baseline) in response to tetanus ( $n=50$ slices, eight mice), very similar to the value of $50 \%$ obtained using slices from the $f B Z / f B Z$ mice ( $n=34$ slices, six mice) (Fig. $6 B$ ). Thus, although TrkB is required for modulation of LTP by BDNF at Schaffer collateral $\rightarrow$ CA1 synapses, deletion of TrkB in the postsynaptic cells does not reduce or eliminate the BDNF effect.

The above results imply that BDNF acts on TrkB receptors in presynaptic CA3 afferent neurons or in interneurons to modulate LTP at the CA1 synapses. Alternatively, one might argue that the reduced level of TrkB in the $f B Z / f B Z$ mice makes residual CA1 LTP unresponsive to changes in endogenous BDNF levels, so that deletion of TrkB within the postsynaptic neurons in the trkB CA1-KO mice would not have a further effect. To determine whether LTP in the trkB CA1-KO mice remains dependent on TrkB activation by endogenous BDNF, we applied the BDNF and NT-4 scavenger TrkB-IgG to the trkB CA1-KO hippocampal slices. As shown in Figure $6 D$, the average magnitude of LTP was further reduced to $120 \pm 1.1 \%$ of baseline after application of TrkB-IgG to slices from the trkB CA1-KO $(n=4$ mice). Because the TrkB receptor was completely absent from $>90 \%$ of the postsynaptic cells of CA1 synapses in these mice, TrkB-IgG can only have inhibited the effect of BDNF on presynaptic CA3 afferent neurons or interneurons.

At the presynaptic sites, BDNF could act directly on CA3 afferents to enhance high-frequency excitatory transmission during the tetanus (Gottschalk et al., 1998; Pozzo-Miller et al., 1999). Alternatively, BDNF might act indirectly on interneurons to attenuate inhibitory transmission (Tanaka et al., 1997; Frerking et al., 1998). Either or both could contribute to the facilitation of LTP. To distinguish between these possibilities, we analyzed synaptic re- sponses to LTP-inducing HFS $(100 \mathrm{~Hz}, 1 \mathrm{sec}$; termed "response to HFS"), a parameter that directly reflects the properties of the presynaptic CA3 terminals (Dobrunz and Stevens, 1997). Compared with wild-type animals, the average response to HFS was reduced by $\sim 25 \%$ at $C A 1$ synapses in both $f B Z / f B Z$ and trkB CA1-KO mice (Fig. 6E). The percentages of the 100th EPSP slope over the first EPSP slope in the HFS trains were $39.0 \pm 3.1 \%$ in wild type (34 slices, 10 mice), $29.6 \pm 1.2 \%$ in $f B Z / f B Z$ (20 slices, six mice), and $31.1 \pm 1.6 \%$ in trkB CA1-KO (40 slices, eight mice) (ANOVA, $p<0.05$ ). These results strongly suggest that TrkB signaling is required within CA3 afferent terminals, although an additional role of TrkB in interneurons cannot be completely excluded. As shown in Figure $6 F$, incubation of slices from wildtype mice with anti-p75NTR IgG does not alter responses of the CA3 afferent terminals to HFS ( $n=4$ for wild-type and $n=5$ for p75 antibody, respectively). These results indicate that BDNF modulates the properties of the CA3 terminals exclusively through TrkB signaling.

\section{Postsynaptic contributions to LTP are not altered in the fBZ/fBZ mutant}

The results obtained with the trkB CA1-KO mutant and TrkB-IgG fusion protein clearly demonstrate that the TrkB signal modulates CA1 LTP in $f B Z / f B Z$ mice through a presynaptic mechanism. However, these data do not exclude the possibility that a postsynaptic mechanism is partially involved in BDNF modulation of LTP in a wild-type mouse, because CA1 LTP has been significantly reduced in $f B Z / f B Z$ mice (Fig. $6 A$ ). To address this issue, we first compared the evoked AMPA receptor (AMPAR)-mediated field EPSPs in the CA1 region from wild-type and $f B Z / f B Z$ mice. To assess the strength of the AMPAR EPSP, we plotted the amplitude of the presynaptic fiber volley (input) against the slope of the field EPSP over a range of stimulus strengths. No significant difference in the input-output curve was found between wild-type and $f B Z$ / $f B Z$ mice (Fig. $7 A$ ), indicating that synaptic transmission mediated by AMPARs was unaltered. We next examined the contribution of NMDA receptors (NMDARs) to synaptic transmission by patch clamping CA1 pyramidal cells at a positive membrane potential so that the NMDAR and AMPAR components of the EPSC could be simultaneously recorded. Responses were recorded in the absence and presence of the NMDAR inhibitor AP-5 so that the relative 
A

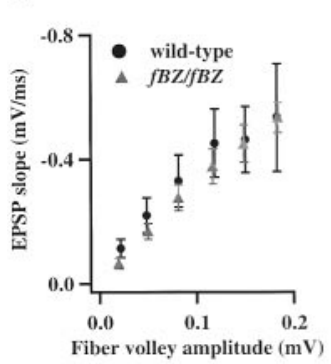

B
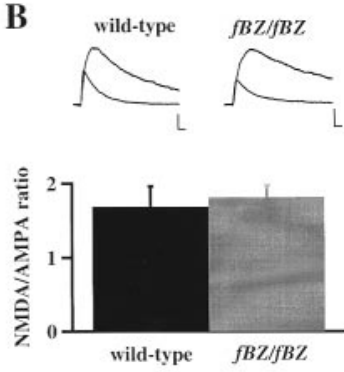

C

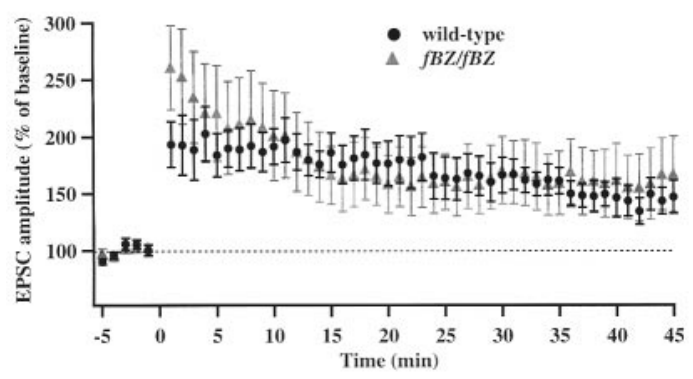

Figure 7. Postsynaptic contributions to LTP are normal in $f B Z / f B Z$ mice. $A$, Input-output relations for wild-type and $f B Z / f B Z$ mutant mice. Field EPSPs were recorded from the stratum radiatum of hippocampal slices at a range of stimulus intensities. Fiber volley amplitudes were binned, and corresponding EPSP slopes were averaged between slices. Measurements were obtained in ACSF containing $100 \mu \mathrm{M}$ D-AP-5. Each point represents the mean \pm SEM for each bin. Wild-type, $n=8 ; f B Z / f B Z, n=7$. $B$, Magnitude of the ratio of NMDA current to AMPA current in CA1 pyramidal cells from $f B Z / f B Z$ and wild-type mice. Cells were clamped at $+30 \mathrm{mV}$, and afferent fibers were stimulated to evoke dual-component EPSCs; $50 \mu \mathrm{M}$ D-AP-5 was then added to the perfusion medium, and afferent stimulation was continued at the same intensity. The average NMDA-only EPSC was derived by subtracting the average AMPA-only EPSC from the average dual-component EPSC. Wild type, $n=9 ; f B Z / f B Z$, $n=13$. Insets, Representative examples of NMDA-only and AMPA-only EPSCs from mice of each genotype. Calibration: $20 \mathrm{pA}, 10 \mathrm{msec}$. $C$, Time course of synaptic potentiation induced by a "pairing" protocol. Evoked EPSCs were recorded at $0.1 \mathrm{~Hz}$ from CA1 pyramidal cells clamped at -60 $\mathrm{mV}$ in whole-cell mode. At time 0 , the cell was depolarized to $0 \mathrm{mV}$ while afferent fibers were stimulated 100 times at $1 \mathrm{~Hz}$, after which the cell was repolarized to $-60 \mathrm{mV}$, and low-frequency stimulation was resumed. Wild type, $n=8 ; f B Z / f B Z, n=10$.

contribution of the two receptor-mediated components could be measured. On the basis of these measurements we calculated an NMDAR current/AMPAR current ratio for both animals. As shown in Figure $7 B$, the NMDAR/AMPAR ratio is not significantly altered in the $f B Z / f B Z$ mutant. These data indicate that basal synaptic transmission, as measured by the AMPAR-mediated field EPSP, is unaltered in the $f B Z / f B Z$ mice. Furthermore, NMDAR function, as measured by the NMDAR current/AMPAR current ratio, is not changed in the mutant mice. Thus, it is unlikely that the reduction in tetanus-induced LTP in the CA1 syanpses of $f B Z / f B Z$ mice is attributable to impairment in postsynaptic NMDAR.

To determine whether other postsynaptic components involved in the induction of CA1 LTP, besides AMPA and NMDA receptors, are modified in the $f B Z / f B Z$ mutant, we induced LTP by a protocol in which postsynaptic depolarization of patch-clamped CA1 pyramidal neurons is paired with low-frequency stimulation of the input fibers. Because the pairing protocol uses low-frequency stimulation and thus avoids sustained high-frequency glutamate release from presynaptic terminals, differences in LTP induced by this protocol reveal differences in a postsynaptic mechanism. In these experiments, CA1 pyramidal cells were clamped at $0 \mathrm{mV}$, whereas 100 stimuli at $1 \mathrm{~Hz}$ were applied to Schaffer collaterals to induce LTP. As shown in Figure $7 C$, no significant difference was detected in pairing-induced CA1 LTP between wild-type and $f B Z /$ $f B Z$ mice. These results show that postsynaptic mechanisms of CA1
LTP generation are not affected by the reduced levels of TrkB in the $f B Z / f B Z$ mice. These results, together with the data demonstrating that tetanus-induced LTP is not further reduced in the trkB CA1-KO compared with $f B Z / f B Z$ (Fig. 6), indicate that reductions in TrkB do not perturb signaling in postsynaptic CA1 pyramidal neurons to limit generation of LTP.

\section{DISCUSSION}

Our results indicate that BDNF modulates LTP by activating TrkB and not p75NTR. A mouse in which TrkB expression is reduced throughout development has been used to demonstrate that hippocampal cells and anatomy are not affected by reductions in TrkB protein levels. In addtion, AMPA and NMDA receptor functions are normal, and LTP can be generated normally by a paired depolarization-low-frequency stimulation protocol. Interestingly, though, synaptic properties of Schaffer collateral terminals in CA1 and tetanus-induced LTP are clearly altered. A second mouse, in which TrkB expression is eliminated in the vast majority of CA1 pyramidal neurons during late postnatal development, has been used to demonstrate that CA1 neurons are quite resistant to deficits in TrkB-mediated signaling. Their morphologies appear normal, and their postsynaptic properties appear to be completely normal. Despite strong evidence that induction and expression of LTP at CA1 synapses are postsynaptic in origin (Bliss and Collingridge, 1993; Isaac et al., 1995; Liao et al., 1995), loss of TrkB within these neurons does not detectably inhibit synaptic plasticity. Thus BDNF signaling through TrkB appears to affect LTP indirectly by controlling the ability of presynaptic terminals to respond to LTPinducing patterns of stimulation.

\section{The reporter gene tau-lacZ identifies trkB mutant neurons}

The concept behind the design of our floxed trkB allele may be generally useful. We have attached the tau-lac $Z$ gene to the floxed trk $B$, resulting in expression of $\beta$-galactosidase specifically in cells in which the trkB gene has been deleted. This has allowed us to monitor the fate of trkB null neurons in a chimeric environment. Lower expression of the TrkB receptor from the $f B Z$ allele in comparison with the wild-type allele was unexpected but made it possible to examine the phenotype resulting from TrkB reduction. The reasons for reduced TrkB expression is not clear. It is possible that insertion of a large trkB cDNA into a small exon causes a decrease in splicing efficiency.

Mice containing a trkB allele and a trkB null allele had significant losses of vestibular sensory neurons and developed more slowly, undoubtedly because they expressed only $12-13 \%$ of the normal amount of TrkB (data not shown). Because mice with two copies of the $f B Z$ allele did thrive and appeared to develop normally, all experiments in this paper used these mice. Although in theory the expression of tau- $\beta$-galactosidase does not distinguish between deletion of one or two copies of the floxed trkB allele, both copies appear to be deleted in $>90 \%$ of the CA1 pyramidal neurons. First, in situ hybridization indicates that only a few scattered cells, the vast majority of which appear to be GABAergic interneurons, express detectable trkB mRNA in CA1. Second, when efficiency of recombination was assayed in a strain with one copy of the floxed trkB allele, the allele was deleted in $96 \%$ of the CA1 pyramidal neurons, as identified by expression of $\beta$-galactosidase. In a background with two copies of the floxed $\operatorname{trk} B$ allele, at least one of these alleles was deleted in $100 \%$ of CA1 pyramidal neurons examined. Assuming independence in recombination of alleles within the same cell, the calculated efficiency of double recombination is $92 \%(0.96 \times 96 \%)$. With most other assumptions, it would be even higher. Thus, two independent lines of evidence indicate that targeting of CA1 pyramidal cells was almost complete. No examples were detected in which other classes of neurons within CA1 were targeted, so recombination appears to be restricted to the CA1 pyramidal neurons. 


\section{Survival and dendritic differentiation of CA1 pyramidal neurons do not require TrkB}

In the trkB CA1-KO mutant, all neurons that express $\alpha \mathrm{CaMKII}$ also express tau- $\beta$-galactosidase, whose expression is controlled by the trkB promoter (Fig. 3). Consequently, all CA1 pyramidal neurons must express TrkB. Previous work has shown that BDNF does not promote survival of embryonic rat hippocampal pyramidal neurons in culture (Ip et al., 1993; Marsh and Palfrey, 1996). Previous work has also indicated that there is not a requirement for BDNF or TrkB for survival of neonatal hippocampal pyramidal neurons in vivo (Jones et al., 1994; Minichiello and Klein, 1996; Alcántara et al., 1997). Results in the present paper extend this work by providing evidence that TrkB is not required for survival of CA1 pyramidal neurons in the mature brain. Furthermore, the dendritic structure of CA1 pyramidal neurons as revealed by immunohistochemistry to MAP2 and tau- $\beta$-galactosidase is apparently not affected by TrkB removal (Fig. 5). This is in contrast to the neocortex, where many pyramidal neurons require TrkB for survival and maintenance of their dendritic structures ( $\mathrm{Xu}$ et al., 2000).

\section{BDNF modulates hippocampal LTP through TrkB}

BDNF modulates LTP as well as synaptic responses to tetanus at Schaffer collateral $\rightarrow$ CA1 synapses (for review, see $\mathrm{Lu}$ and Chow, 1999). An open issue is whether BDNF interacts with TrkB or p75NTR to achieve its modulatory effects. In the $f B Z / f B Z$ hypomorph, expression of TrkB is dramatically reduced throughout the hippocampus, resulting in a significant reduction in both synaptic responses to tetanus and LTP induced by tetanic stimulation. It is highly unlikely that the LTP reduction in the $f B Z / f B Z$ mutant results from subtle developmental abnormalities, because the $f B Z$ / $f B Z$ mutant shows normal pairing-induced LTP and the trkB CA1-KO is sensitive to the TrkB-IgG fusion protein in induction of LTP. Moreover, the deficiencies in LTP generation observed in BDNF mutants are reversed by application of BDNF (Korte et al., 1996; Patterson et al., 1996). Thus the present study clearly implicates TrkB as a mediator for BDNF modulation of synaptic plasticity in the hippocampus. In contrast, BDNF signaling through p75NTR almost certainly does not mediate synaptic plasticity, because application to slices of p75NTR-blocking antibodies does not impair LTP. These same antibodies have been shown to be effective at inhibiting P75NTR-mediated signaling in vivo (LucidiPhillipi et al., 1996), Using an independently generated floxed trkB mouse, Minichiello et al. (1999) have also observed reductions in LTP as a consequence of reducing or deleting $\operatorname{trk} B$ throughout the hippocampus.

\section{TrkB modulates LTP signaling in presynaptic CA3 but not postsynaptic CA1 neurons}

Substantial evidence supports a role for BDNF in hippocampal LTP (for review, see Lu and Chow, 1999; McAllister et al., 1999), and our results indicate that it acts through the TrkB receptor. An issue under debate is whether the TrkB-mediated signaling relevant to generation of LTP is presynaptic or postsynaptic. Previous studies have suggested that BDNF facilitates LTP by enhancing synaptic release to tetanic stimulation, possibly by promoting docking of synaptic vesicles to the presynaptic membrane at CA1 synapses (Gottschalk et al., 1998; Pozzo-Miller et al., 1999). In contrast, BDNF has been shown to enhance postsynaptic responsiveness in cultured hippocampal neurons by enhancing transmission through postsynaptic NMDA receptor channels (Levine et al., 1995, 1998). BDNF also decreases inhibitory postsynaptic currents on CA1 pyramidal cells (Tanaka et al., 1997; Frerking et al., 1998), so a reduction in inhibitory inputs to CA1 neurons may contribute to LTP generation. Furthermore, a recent paper demonstrated that BDNF, when rapidly puffed onto the CA1 pyramidal neurons, induces direct depolarization (Kafitz et al., 1999), which suggests that a direct, excitatory effect of BDNF on the postsynaptic CA1 cells may contribute to LTP. Several results in the present paper argue that TrkB deficiency does not affect the properties of postsynaptic CA1 pyramidal neurons necessary for generation of LTP. First, despite the observed reduction in tetanus-induced LTP in the $f B Z / f B Z$ mouse, the AMPAR and NMDAR currents in CA1 pyramidal neurons are not different from those of the same receptors in wild-type controls. Second, LTP is generated normally in $f B Z / f B Z$ hippocampi by pairing postsynaptic cell depolarization with low-frequency stimulation of CA3 input fibers, a protocol that specifically assesses properties of postsynaptic cells. Finally, our results demonstrate that specific deletion of TrkB receptors in postsynaptic pyramidal neurons in the $f B Z / f B Z$ background has no additional inhibitory effect on LTP generation by tetanic stimulation. LTP remains dependent on TrkB signaling in this genetic background, however, because application of the BDNF and NT-4 scavenger TrkB-IgG does have an inhibitory effect on tetanic stimulation-induced LTP. If not the postsynaptic cells, BDNF could in principle be affecting either the Schaffer collaterals or the interneurons. The impairment of synaptic responses to tetanus in both $f B Z / f B Z$ and $t r k B$ CA1-KO mice argues for a direct modulation of CA3 afferents by BDNF activation of TrkB, although we cannot rule out an additional role of TrkB in GABAergic interneurons. Taken together, these results strongly suggest that BDNF acts presynaptically to modulate LTP in the CA1 region. Because the major locus for the induction and expression of LTP appears to be the postsynaptic cell in the CA1 region (Bliss and Collingridge, 1993; Isaac et al., 1995; Liao et al., 1995), our results suggest that BDNF signaling is not directly involved in the biochemical changes underlying LTP within the postsynaptic cells but instead modulates the competence of presynaptic neurons to generate the repetitive exocytotic events needed to modify the long-term responses of the postsynaptic neurons. Experiments that delete the trkB gene in CA3 pyramidal neurons and interneurons should confirm these conclusions.

\section{REFERENCES}

Alcántara S, Frisén J, del Río JA, Soriano E, Barbacid M, Silos-Santiago I (1997) TrkB signaling is required for postnatal survival of CNS neurons and protects hippocampal and motor neurons from axotomy-induced cell death. J Neurosci 17:3623-3633.

Altar CA, Siuciak JA, Wright P, Ip NY, Lindsay RM, Wiegand SJ (1994) In situ hybridization of trkB and trkC receptor mRNA in rat forebrain and association with high-affinity binding of [125I]BDNF, [125I]NT-4/5 and [125I]NT-3. Eur J Neurosci 6:1389-1405.

Bliss TVP, Collingridge GL (1993) A synaptic model of memory: longterm potentiation in the hippocampus. Nature 361:31-39.

Burgin KE, Waxham MN, Rickling S, Westgate SA, Mobley WC, Kelly PT (1990) In situ hybridization histochemistry of $\mathrm{Ca}^{2+} /$ calmodulindependent protein kinase in developing rat brain. J Neurosci 10:1788-1798.

Callahan CA, Thomas JB (1994) Tau-beta-galactosidase, an axontargeted fusion protein. Proc Natl Acad Sci USA 91:5972-5976.

Dobrunz LE, Stevens CF (1997) Heterogeneity of release probability, facilitation, and depletion at central synapses. Neuron 18:995-1008.

Fariñas I, Yoshida CK, Backus C, Reichardt LF (1996) Lack of neurotrophin-3 results in death of spinal sensory neurons and premature differentiation of their precursors. Neuron 17:1065-1078.

Figurov A, Pozzo-Miller L, Olafsson P, Wang T, Lu B (1996) Regulation of synaptic responses to high-frequency stimulation and LTP by neurotrophins in the hippocampus. Nature 381:706-709.

Frerking M, Malenka RC, Nicoll RA (1998) Brain-derived neurotrophic factor (BDNF) modulates inhibitory, but not excitatory, transmission in the CA1 region of the hippocampus. J Neurophysiol 80:3383-3386.

Gottschalk W, Pozzo-Miller LD, Figurov A, Lu B (1998) Presynaptic modulation of synaptic transmission and plasticity by brain- derived neurotrophic factor in the developing hippocampus. J Neurosci 18:6830-6839.

Gu H, Marth JD, Orban PC, Mossmann H, Rajewsky K (1994) Deletion of a DNA polymerase $\beta$ gene segment in T cells using cell type-specific gene targeting. Science 265:103-106.

Huang EJ, Wilkinson GA, Fariñas I, Backus C, Zang K, Wong SL, Reichardt LF (1999) Expression of Trk receptors in the developing mouse trigeminal ganglion: in vivo evidence for NT-3 activation of TrkA and TrkB in addition to TrkC. Development 126:2191-2203.

Ip NY, Li Y, Yancopoulos GD, Lindsay RM (1993) Cultured hippocampal neurons show responses to BDNF, NT-3, and NT-4, but not NGF. J Neurosci 13:3394-3405.

Isaac JTR, Nicoll RA, Malenka RC (1995) Evidence for silent synapses: implications for the expression of LTP. Neuron 15:427-434.

Jarvis CR, Xiong ZG, Plant JR, Churchill D, Lu WY, Macvicar BA, 
Macdonald JF (1997) Neurotrophin modulation of NMDA receptors in cultured murine and isolated rat neurons. J Neurophysiol 78:2363-2371.

Jones KR, Farinas I, Backus C, Reichardt LF (1994) Targeted disruption of the BDNF gene perturbs brain and sensory neuron development but not motor neuron development. Cell 76:989-999.

Kafitz KW, Rose CR, Thoenen H, Konnerth A (1999) Neurotrophinevoked rapid excitation through TrkB receptors. Nature 401:918-922.

Kang H, Schuman EM (1995) Long-lasting neurotrophin-induced en hancement of synaptic transmission in the adult hippocampus. Science 267:1658-1662.

Kang H, Welcher AA, Shelton D, Schuman EM (1997) Neurotrophins and time: different roles for TrkB signaling in hippocampal long-term potentiation. Neuron 19:653-664.

Klein R, Conway D, Parada LF, Barbacid M (1990) The trkB tyrosine protein kinase gene codes for a second neurogenic receptor that lacks the catalytic kinase domain. Cell 61:647-656.

Korsching S (1993) The neurotrophic factor concept: a reexamination. J Neurosci 13:2739-2748.

Korte M, Carroll P, Wolf E, Brem G, Thoenen H, Bonhoeffer T (1995) Hippocampal long-term potentiation is impaired in mice lacking brainderived neurotrophic factor. Proc Natl Acad Sci USA 92:8856-8860.

Korte M, Griesbeck O, Gravel C, Carroll P, Staiger V, Thoenen H, Bonhoeffer T (1996) Virus-mediated gene transfer into hippocampal CA1 region restores long-term potentiation in brain-derived neurotrophic factor mutant mice. Proc Natl Acad Sci USA 93:12547-12552.

Lessmann V, Gottmann K, Heumann R (1994) BDNF and NT-4/5 enhance glutamatergic synaptic transmission in cultured hippocampal neurons. NeuroReport 6:21-25.

Levine ES, Dreyfus CF, Black IB, Plummer MR (1995) Brain-derived neurotrophic factor rapidly enhances synaptic transmission in hippocampal neurons via postsynaptic tyrosine kinase receptors. Proc Natl Acad Sci USA 92:8074-8077.

Levine ES, Crozier RA, Black IB, Plummer MR (1998) Brain-derived neurotrophic factor modulates hippocampal synaptic transmission by increasing $N$-methyl-D-aspartic acid receptor activity. Proc Natl Acad Sci USA 95:10235-10239.

Li YX, Zhang Y, Lester HA, Schuman EM, Davidson N (1998) Enhancement of neurotransmitter release induced by brain-derived neurotrophic factor in cultured hippocampal neurons. J Neurosci 18:10231-10240.

Liao D, Hessler NA, Malinow R (1995) Activation of postsynaptically silent synapses during pairing-induced LTP in CA1 region of hippocampal slice. Nature 371:400-404.

Lohof AM, Ip NY, Poo MM (1993) Potentiation of developing neuromuscular synapses by the neurotrophins NT-3 and BDNF. Nature 363:350-353.

Lu B, Chow A (1999) Neurotrophins and hippocampal synaptic plasticity. J Neurosci Res 58:76-87.

Lucidi-Phillipi CA, Clary DO, Reichardt LF, Gage FH (1996) TrkA activation is sufficient to rescue axotomized cholinergic neurons. Neuron 16:653-663.

Malenka RC, Nicoll RA (1999) Long-term potentiation-a decade of progress? Science 285:1870-1874.

Marsh HN, Palfrey HC (1996) Neurotrophin-3 and brain-derived neurotrophic factor activate multiple signal transduction events but are not survival factors for hippocampal pyramidal neurons. J Neurochem 67:952-963.

Mayford M, Wang J, Kandel ER, O'Dell TJ (1995) CaMKII regulates the frequency-response function of hippocampal synapses for the production of both LTD and LTP. Cell 81:891-904.
McAllister AM, Katz LC, Lo DC (1999) Neurotrophins and synaptic plasticity. Annu Rev Neurosci 22:295-318.

Minichiello L, Klein R (1996) TrkB and TrkC neurotrophin receptors cooperate in promoting survival of hippocampal and cerebellar granule neurons. Genes Dev 10:2849-2858.

Minichiello L, Korte M, Wolfer D, Kühn R, Unsicker K, Cestari V, Rossi-Arnaud C, Lipp HP, Bonhoeffer T, Klein R (1999) Essential role for TrkB receptors in hippocampus-mediated learning. Neuron 24:401-414.

Muller U, Wang D, Denda S, Meneses JJ, Pedersen RA, Reichardt LF (1997) Integrin alpha8beta1 is critically important for epithelialmesenchymal interactions during kidney morphogenesis. Cell 88:603-613.

Patterson SL, Abel T, Deuel TA, Martin KC, Rose JC, Kandel ER (1996) Recombinant BDNF rescues deficits in basal synaptic transmission and hippocampal LTP in BDNF knockout mice. Neuron 16:1137-1145.

Pioro EP, Cuello AC (1990) Distribution of nerve growth factor receptorlike immunoreactivity in the adult rat central nervous system. Effect of colchicine and correlation with the cholinergic system-II. Brainstem, cerebellum and spinal cord. Neuroscience 34:89-110.

Pozzo-Miller LD, Gottschalk W, Zhang L, McDermott K, Du J, Gopalakrishnan R, Oho C, Sheng ZH, Lu B (1999) Impairments in high frequency transmission, synaptic vesicle docking and synaptic protein distribution in the hippocampus of BDNF knockout mice. J Neurosci 19:4972-4983.

Reichardt LF, Fariñas I (1997) Neurotrophic factors and their receptors: roles in neuronal development and function. In: Molecular approaches to neural development (Cowan MW, Jessell TM, Zipurski L, eds), pp. 220-263. New York: Oxford UP.

Shetty AK, Turner DA (1998) Hippocampal interneurons expressing glutamic acid decarboxylase and calcium-binding proteins decrease with aging in Fischer 344 rats. J Comp Neurol 394:252-269.

Sík A, Hájos N, Gulácsi A, Mody I, Freund TF (1998) The absence of a major $\mathrm{Ca}^{2+}$ signaling pathway in GABAergic neurons of the hippocampus. Proc Natl Acad Sci USA 95:3245-3250.

Tanaka T, Saito H, Matsuki N (1997) Inhibition of GABAa synaptic responses by brain-derived neurotrophic factor (BDNF) in rat hippocampus. J Neurosci 17:2959-2966.

Thoenen H (1995) Neurotrophins and neuronal plasticity. Science 270:593-596.

Tsien JZ, Chen DF, Gerber D, Tom C, Mercer EH, Anderson DJ, Mayford M, Kandel ER, Tonegawa S (1996) Subregion- and cell type-restricted gene knockout in mouse brain. Cell 87:1317-1326.

Vicario-Abejón C, Collin C, McKay RDG, Segal M (1998) Neurotrophins induce formation of functional excitatory and inhibitory synapses between cultured hippocampal neurons. J Neurosci 18:7256-7271.

$\mathrm{Xu} \mathrm{B}$, Zang K, Ruff NL, Zhang YA, McConnell SK, Stryker MP, Reichardt LF (2000) Cortical degeneration in the absence of neurotrophin signaling in the adult neocortex. Dendritic retraction and neuronal loss after removal of the neurotrophin receptor TrkB. Neuron 26:233-245.

Yan Q, Radeke MJ, Matheson CR, Talvenheimo J, Welcher AA, Feinstein SC (1997) Immunocytochemical localization of TrkB in the central nervous system of the adult rat. J Comp Neurol 378:135-157.

Zhang W, Vazquez L, Apperson M, Kennedy MB (1999) Citron binds to PSD-95 at glutamatergic synapses on inhibitory neurons in the hippocampus. J Neurosci 19:96-108. 